\title{
Use of plasma ferritin concentration to diagnose iron deficiency in elderly patients
}

\author{
T L Holyoake, D J Stott, P J McKay, A Hendry, J B MacDonald, N P Lucie
}

\begin{abstract}
Aims-To determine a concentration of ferritin below which the possibility of iron deficiency should be considered in elderly patients.
\end{abstract}

Methods-Consecutive new referrals to a geriatric unit $(n=472)$ were studied prospectively. Full blood count, ferritin, serum vitamin $B 12$ and red cell folate were measured for all patients. A blood film was assessed independently by three haematologists for features of iron deficiency. For those with ferritin of 12-45 $\mathrm{ng} / \mathrm{ml}$, bone marrow aspirates were performed and examined for the presence of stainable iron. When possible, a trial of oral iron was given to those with ferritin of $\leqslant 45 \mathrm{ng} / \mathrm{ml}$ and response was determined by remeasurement of full blood count and ferritin after a minimum of three weeks of treatment.

Results-Bone marrow examination was performed in 32 patients with ferritin of $12-45 \mathrm{ng} / \mathrm{ml}$, of whom $27(84 \%)$ had absent stainable iron, suggesting that most elderly patients with ferritin in this range have iron deficiency. Compared with those with ferritin of 100-299 $\mathrm{ng} / \mathrm{ml}$, in whom iron stores were presumed to be normal, patients with ferritin of 12-45 $\mathrm{ng} / \mathrm{ml}$ had a significantly lower mean haemoglobin and mean red blood cell volume. Furthermore, patients with ferritin up to $75 \mathrm{ng} / \mathrm{ml}$ had a significantly higher mean red cell distribution width, and were more likely to have an iron deficient blood film.

Conclusion-Iron deficient erythropoiesis can occur in elderly patients with ferritin up to $75 \mathrm{ng} / \mathrm{ml}$. This is much higher than the lower limit of the "normal" range usually quoted for younger subjects; this difference should be taken into account when ferritin concentrations are interpreted in elderly patients.

$(尹$ Clin Pathol 1993;46:857-860)

The diagnosis of iron deficiency from the full blood count is often difficult in elderly patients. Multiple pathology is common in old age, and iron deficiency and the anaemia of chronic disease may both be present. A hypochromic microcytic anaemia in association with characteristic blood film appearances is suggestive of iron deficiency. All of these features, however, can be caused by malignancy, chronic sepsis, rheumatoid arthritis or renal failure. ${ }^{12}$ Furthermore, in early iron deficiency the only abnormality in the full blood count may be a non-specific mild normochromic normocytic anaemia. ${ }^{3}$ Finally, patients may have latent iron deficiency, with absent bone marrow iron stores, but erythropoiesis remains unaffected and the full blood count is normal. ${ }^{3}$ Therefore, in elderly patients, iron deficiency of any severity cannot be diagnosed reliably from the full blood count alone.

The "gold standard" for the diagnosis of iron deficiency is confirmation of absence of iron stores in a bone marrow aspirate sample. Bone marrow aspiration, however, is invasive, and time consuming for laboratory staff. Measurement of serum or plasma ferritin is the best single blood test for the diagnosis of iron deficiency, but its interpretation in elderly patients is complicated by a tendency for it to rise with both ageing ${ }^{4}$ and various chronic diseases. Studies of elderly anaemic patients have suggested that the diagnosis of iron deficiency is likely in those with ferritin of $\leqslant 45 \mathrm{ng} / \mathrm{ml}$, compared with the lower concentration of $\leqslant 12 \mathrm{ng} / \mathrm{ml}$ for young adults. ${ }^{5}$

We have studied further the association between plasma ferritin, the full blood count, and the blood film with iron deficiency in a large cohort of elderly patients referred to a geriatric medical unit. In particular, we aimed to determine a level of plasma ferritin below which the possibility of iron deficiency and iron deficient erythropoiesis should be considered.

\section{Methods}

We studied prospectively 472 consecutive new referrals to a geriatric medical unit. They comprised 330 inpatients and 142 outpatients or day hospital attenders. There were 333 women (mean age 82, range 63-101 years) and 139 men (mean age 79, range 62-94 years).

A standard venous blood sample was taken from all patients for full blood count (Coulter $S$ Plus IV), plasma ferritin (immunoradiometric assay, Ciba-Corning), serum vitamin B12, red cell folate (radiosorbent assays, Becton Dickinson) erythrocyte sedimentation rate (ESR, Westergren), serum urea and electrolytes, liver function tests, calcium and phosphate, blood sugar, thyroxine and thyroid stimulating hormone. Other investigations were performed depending on the clinical presentation and the results of the 
Table 1 Association between plasma ferritin and full blood count indices and blood film in elderly patients

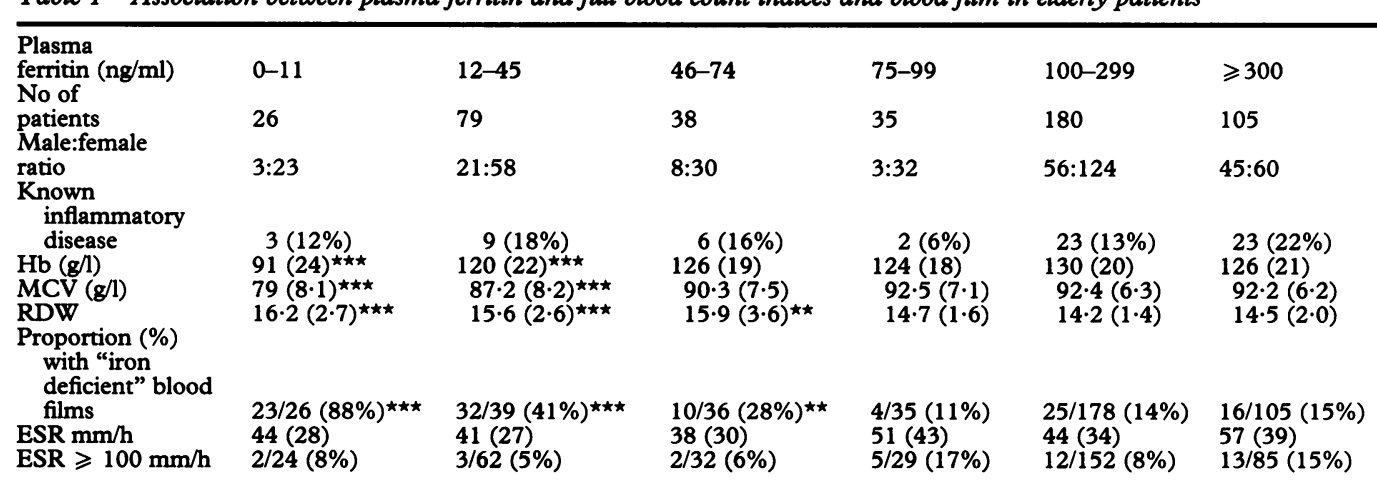

$\star \star \star \mathrm{p} \leqslant 0.001,{ }^{\star \star} \mathrm{p} \leqslant 0.01$ compared with group with ferritin $100-299 \mathrm{ng} / \mathrm{ml}$.

$\mathrm{Hb}=$ haemoglobin

$\mathrm{MCV}=$ mean cell volume

RDW $=$ red cell distribution width

above blood tests. Patients found to have malignancy $(n=39)$, inflammatory joint disease $(n=12)$, other connective tissue diseases $(n=4)$, or chronic sepsis $(n=14)$ were coded as having chronic inflammatory disease ( $n=67$, two patients each had two conditions coded).

A blood film was assessed (without knowing the results of the full blood count and plasma ferritin) independently by three haematologists, and graded as features suggestive of iron deficiency, or no evidence of iron deficiency; in cases of disagreement the film was reviewed by all three and a consensus view obtained for final statistical analysis.

Patients with plasma ferritin of 12-45 $\mathrm{ng} / \mathrm{ml}$ were considered to have possible iron deficiency, and consent for bone marrow aspiration was requested. Bone marrow aspirate was stained by Perls's Prussian blue method and iron stores were then graded as present or absent.

Where possible, the response to iron was assessed in patients with plasma ferritin of $\leqslant 45 \mathrm{ng} / \mathrm{ml}$; iron was given for a minimum of three weeks and full blood count and serum ferritin were then remeasured. A rise in haemoglobin of $\geqslant 10 \mathrm{~g} / 1$ on this single further reading was accepted as a positive response to iron, and those in whom it rose by $<10 \mathrm{~g} / 1$ were designated as non-responders. Patients who received blood transfusion and those who received intramuscular vitamin $\mathrm{B} 12$ or oral folic acid were excluded from this analysis.

Statistical analyses were by the Wilcoxon rank sum test, Student's unpaired $t$ test (2tailed), and the $\chi^{2}$ test. Differences were accepted as significant at the $5 \%$ level of probability. Results are expressed as mean (1 standard deviation) except where otherwise stated.

\section{Results}

Plasma ferritin and haemoglobin concentrations were significantly higher in men than in women (men: median ferritin $199 \mathrm{ng} / \mathrm{ml}$, mean haemoglobin 132 (24) $\mathrm{g} / \mathrm{l}$; women: median ferritin $117 \mathrm{ng} / \mathrm{ml}$, mean haemoglobin $122(21 \mathrm{~g} / 1)$; Wilcoxon rank sum test $\mathrm{p}<0.004$ and $\mathrm{p}<0.001$, respectively).

Bone marrow examination was performed in 32 of 78 patients with ferritin of $12-45$ $\mathrm{ng} / \mathrm{ml} ; 27$ of $32(84 \%)$ had absent stainable iron. Patients with plasma ferritin of $\leqslant 45$ $\mathrm{ng} / \mathrm{ml}$ had a significantly lower haemoglobin concentration and mean red blood cell volume (MCV) compared with those with ferritin of $100-299 \mathrm{ng} / \mathrm{ml}$ in whom iron stores were presumed to be normal (table 1). Furthermore, patients with plasma ferritin up to $75 \mathrm{ng} / \mathrm{ml}$ had a significantly higher red cell distribution width (RDW, an index of red blood cell size heterogeneity), and an increased proportion of individuals with blood films suggestive of iron deficiency (table 1). Exclusion of the 67 patients identified as having chronic inflammatory disease did not affect these results.

A total of 38 of 472 patients had an MCV of $<80 \mathrm{fl}$; in 33 of these the ferritin was $\leqslant 75$ $\mathrm{ng} / \mathrm{ml}$, and in the remaining five the ferritin was $\geqslant 100 \mathrm{ng} / \mathrm{ml}$. There was a history of chronic inflammatory disease or an unexplained increase in ESR $(\geqslant 100 \mathrm{~mm} / \mathrm{h})$ in four of five of these patients with an MCV of $<80 \mathrm{fl}$ and ferritin of $\geqslant 100 \mathrm{ng} / \mathrm{ml}$.

Of 41 patients with serum ferritin of $\geqslant 100$ $\mathrm{ng} / \mathrm{ml}$ who had features of iron deficiency on blood film examination, only 15 had known chronic inflammatory disease, and one further patient had an increased ESR of $\geqslant 100$ $\mathrm{mm}$ in the first hour that was unexplained.

In $66(14 \%)$ of patients all three haematologists agreed that the blood film appearances were consistent with iron deficiency, and in $311(66 \%)$ all agreed the film was normal. This left $91(19 \%)$ patients in whom there was disagreement about the presence or absence of iron deficiency on blood film examination.

The haematological response to iron (oral administration $n=48$, intramuscular administration $n=2$ ) was assessed in 50 patients with plasma ferritin of $\leqslant 45 \mathrm{ng} / \mathrm{ml}$. A median total dose of $5 \cdot 0$ (range $3 \cdot 8-11 \cdot 3$ ) $\mathrm{g}$ of elemental iron was given over a median time of 
Table 2 Baseline haematology in 50 elderly patients with plasma ferritin $\leqslant 45 \mathrm{ng} / \mathrm{ml}$

\begin{tabular}{lcc}
\hline & "Responders" & "Non-responders" \\
\hline No of & & \\
patients & 23 & 27 \\
Hb $(g / 1)$ & $102(19) \star \star \star$ & $127(19)$ \\
MCV $(f)$ & $80 \cdot 7(8 \cdot 5)^{\star \star \star}$ & $88 \cdot 4(5 \cdot 7)$ \\
RDW & $17 \cdot 0(2 \cdot 1)^{\star \star}$ & $14 \cdot 8(2 \cdot 6)$ \\
Ferritin $(\mathrm{ng} / \mathrm{ml})$ & $19 \cdot 7(12 \cdot 7)^{\star}$ & $28 \cdot 1(11 \cdot 8)$ \\
Number $(\%)$ with & & \\
"iron deficient" & & $7(26 \%)$ \\
blood films & $19(83 \%)^{\star \star \star}$ & $7(2)$ \\
\hline
\end{tabular}

${ }^{\star} \mathrm{p}<0.05^{\star \star} \mathrm{p}<0.01{ }^{\star \star \star} \mathrm{p} \leqslant 0.001$.

$\mathrm{Hb}=$ haemoglobin.

$M C V=$ mean cell volume

RDW = red cell distribution width

Comparing "responders" (those in whom $\mathrm{Hb}$ rose by $\geqslant 10 \mathrm{~g} /$

after a minimum of 3 weeks of iron treatment) with "nonresponders" (those in whom haemoglobin rose by $\geqslant 10 \mathrm{~g} / \mathrm{l}$ ).

four (range three to nine) weeks. With iron treatment there was a rise in haemoglobin of $11.8(18.9) \mathrm{g} / \mathrm{l}$ from a baseline of 115.8 $(22 \cdot 5) \mathrm{g} / \mathrm{l}$, an increase in MCV of $2 \cdot 1(5 \cdot 9) \mathrm{fl}$ (baseline $84.8(8 \cdot 1) \mathrm{fl}$ ) and plasma ferritin rose by 49 (69) $\mathrm{ng} / \mathrm{ml}$ (baseline 24 (13) $\mathrm{ng} / \mathrm{ml})$. Patients who responded to oral iron with an increase in haemoglobin of $\geqslant 10 \mathrm{~g} / 1$ had significantly lower baseline mean MCV and ferritin, higher mean RDW, and were more likely to have a blood film suggestive of iron deficiency, when compared with patients who did not respond (those with an increase in haemoglobin of $<10 \mathrm{~g} / \mathrm{l}$ ) (table 2). There was a large overlap between responders and non-responders in most of these variables, but a response to iron was seen in 19 of 26 (73\%) of patients with changes suggestive of iron deficiency on their blood films, compared with only four of $24(17 \%)$ of those with normal films.

\section{Discussion}

There was good evidence to suggest that a plasma ferritin of $\leqslant 45 \mathrm{ng} / \mathrm{ml}$ usually indicated iron deficiency and was often associated with iron deficient erythropoiesis; $84 \%$ of patients with ferritin of $12-45 \mathrm{ng} / \mathrm{ml}$ who had a bone marrow examination performed had absent stainable marrow iron stores; a plasma ferritin of $\leqslant 45 \mathrm{ng} / \mathrm{ml}$ was associated with reductions of haemoglobin and $\mathrm{MCV}$, a raised $\mathrm{RDW}$, and an increased prevalence of iron deficient blood films. About half the patients with ferritin of $\leqslant 45 \mathrm{ng} / \mathrm{ml}$ who were treated with iron responded with a rise in haemoglobin of $\geqslant 10 \mathrm{~g} / 1$. The non-responders are likely to be patients with latent iron deficiency or to be only very mildly affected by erythropoiesis, although a few may have failed to respond due to poor absorption of iron or continuing gastrointestinal blood loss.

Although we have further established the validity of a plasma ferritin of $\leqslant 45 \mathrm{ng} / \mathrm{ml}$ as indicating likely iron deficiency, this may not be the most appropriate cutoff point to exclude this diagnosis. Indeed, we found that a plasma ferritin of up to $75 \mathrm{ng} / \mathrm{ml}$ was associated with a raised mean $\mathrm{RDW}$ and an increased prevalence of iron deficient blood films. A raised RDW is thought to be a more sensitive measure for early iron deficiency than MCV or mean cell haemoglobin concentration. ${ }^{6}$ Therefore, our results suggest that iron deficiency should be considered in elderly patients with plasma ferritin up to 75 $\mathrm{ng} / \mathrm{ml}$. Similar results have been reported from a study of anaemic elderly patients, in which absent bone marrow iron stores were found in $64 \%$ and $21 \%$ of those with ferritins of $18-45 \mathrm{ng} / \mathrm{ml}$ and $46-100 \mathrm{ng} / \mathrm{ml}$, respectively. 5

An initial MCV of <80fl was highly likely to be associated with iron deficiency, particularly when those patients with known chronic inflammatory disease or a grossly raised ESR were excluded; in these circumstances measurement of serum ferritin may be unnecessary. Pronounced microcytosis, however, was present in only a minority of those with iron deficiency, limiting the utility of the MCV as a diagnostic acid.

We found that a high percentage $(22 \%)$ of patients had a serum ferritin of $\geqslant 300 \mathrm{ng} / \mathrm{ml}$. This is likely to be due to a combination of the effects of ageing and the burden of acute and chronic illness within this population. Ferritin is an acute phase reactant and increases dramatically in acute as well as chronic illness. ${ }^{7}$ Ageing has a separate and additional effect, however, causing a rise in serum or plasma ferritin. ${ }^{4}$

The classic blood film appearances of red blood cell anisocytosis, poikilocytosis (including elongated cells), and hypochromia had poor specificity for iron deficiency when the blood film was interpreted in the absence of other haematological data. About $15 \%$ of patients with serum ferritin of $\geqslant 100 \mathrm{ng} / \mathrm{ml}$ had blood film features suggestive of iron deficiency; these findings could be attributed to chronic inflammatory disease in less than half of these patients. Other investigators have reported variability in the reporting of anisocytosis $^{8}$ and red blood cell fragments 9 on blood films. Furthermore, some features suggestive of iron deficiency can be due to artefacts produced in the preparation and staining of films. ${ }^{10} \mathrm{It}$ is clear that patients with mild anaemia and blood film features of iron deficiency cannot be assumed to have iron deficiency; measurement of serum ferritin to clarify iron status is indicated in such individuals. The blood film was of some value, however, in determining whether patients with low serum ferritin ( $\leqslant 45 \mathrm{ng} / \mathrm{ml}$ ) would have a haematological response to iron. Patients with a normal blood film were unlikely to respond, while a haematological response to iron occurred in most patients with blood film appearances consistent with iron deficiency.

Accurate diagnosis of iron deficiency anaemia is important as it can be readily treated with iron, and, even more importantly, as it is often caused by chronic gastrointestinal blood loss. ${ }^{11}$ The pickup rate of treatable gastrointestinal pathology on endoscopy or barium studies is as high as $66 \%$ in elderly patients with iron deficiency anaemia and a haemoglobin of $<100 \mathrm{~g} / 1 .{ }^{12}$ 
The value of investigating the gastrointestinal tracts of elderly patients with mild iron deficiency anaemia or latent iron deficiency is unclear.

In conclusion, this study provides evidence that iron deficient erythropoiesis can occur in elderly patients with plasma ferritin up to 75 $\mathrm{ng} / \mathrm{ml}$. This is much higher than the lower limit of the "normal" or reference range usually quoted for young subjects; this difference should be taken into account when plasma ferritin concentrations are interpreted in elderly patients.

1 Lipschitz DA. The anemia of chronic disease. $f A m$ Geriatr Soc 1990;38:1258-64.

2 Cash JM, Sears DA. The anemia of chronic disease: spectrum of associated diseases in a series of unselected spectrum of associated diseases in a series of uns
hospitalized patients. Am $\mathcal{Y}$ Med 1989;87:638-44.
3 Schultz BM, Freedman ML. Iron deficiency in the elderly. Baillières Clin Haematol 1987;1:291-313.

4 Casale G, Bonora C, Migliavacca A, Zurita IE, de Nicola P. Serum ferritin and ageing. Age Ageing 1981;10 119-22

5 Guyatt GH, Patterson C, Ali M, et al. Diagnosis of irondeficiency anemia in the elderly. Am F Med 1990;88. 205-9.

6 McClure S, Custer E, Bessman JD. Improved detection of early iron deficiency in nonanemic subjects. $\mathscr{F} A M A$ 1985;253:1021-3.

7 Witte DL. Can serum ferritin be effectively interpreted in the presence of the acute-phase response? Clin Chem the presence of

8 Simel DL, DeLong ER, Feussner JR, Weinberg JB, Crawford J. Erythrocyte anisocytosis. Visual inspection of blood films vs automated analysis of red blood cell distribution width. Arch Intern Med 1988;148:822-4. 9 Bessman JD. Red blood cell fragmentation. Improved 1988;90:268-73.

10 Lewis SM. Blood film evaluations as a quality control activity. Clin Lab Haematol 1990;12(Suppl 1):119-27.

11 Cook IJ, Pavli P, Riley JW, Goulston KJ, Dent OF. Gastrointestinal investigation of iron deficiency anaemia. Br Med f 1986;292:1380-2.

12 Croker JR, Beynon G. Gastro-intestinal bleeding-a major cause of iron deficiency in the elderly. Age Ageing major cause of 